\title{
Does human serotonin-1A receptor polymorphism (rs6295) code for pain and associated symptoms in fibromyalgia syndrome?
}

\author{
S. Tanwar ${ }^{1}$, B. Mattoo ${ }^{1}$, U. Kumar ${ }^{2}$, R. Dada ${ }^{3}$, R. Bhatia ${ }^{1}$ \\ ${ }^{1}$ Department of Physiology; ' $D$ epartment of Rheumatology; and ${ }^{3}$ Department of Anatomy, \\ All India Institute of Medical Sciences (AlIMS), New Delhi, India
}

\section{SUMMARY}

Genetic predisposition may play an important role in the development of fibromyalgia syndrome (FMS). Serotonin is known to be involved in pain modulation and serotonin-1A receptor plays a considerable role in determining the central 5-HT tone. Consequently, variation in 5-HT1A receptor gene (HTR1A) may be responsible for inter-individual variability in pain sensitivity and other clinical symptoms of FMS. Therefore, the objectives of this research work were to study the gene polymorphism of 5-HTRlA gene and to explore the correlation between rs6295 genotype (-1019C/G HTR1A) and duration of pain, pain intensity and pain related depression and anxiety, if any, in FMS.

5-HTR1A genotype for the C(-1019)G polymorphism was typed in 62 patients with FMS and 42 healthy subjects. Present pain intensity, components of pain and pain related depression and anxiety were assessed using the numerical pain rating scale, McGill pain questionnaire and Hamilton depression and anxiety rating scale respectively.

5-HTR1A gene was represented by three different genotypes, homozygous $\mathrm{C} / \mathrm{C}$, heterozygous $\mathrm{C} / \mathrm{G}$ and homozygous G/G. Analysis of the 5-HTR1A gene showed a frequency of 58\%,31\% and $11 \%$ for the $\mathrm{C} / \mathrm{C}, \mathrm{C} / \mathrm{G}$ and $\mathrm{G} / \mathrm{G}$ genotypes, respectively in FMS group. This proportion was $69 \%, 23 \%$ and $8 \%$ in healthy subjects. No significant correlation was observed between 5-HTR1A gene polymorphism and pain and related symptoms in FMS patients.

To the best of our knowledge this is the first study which investigated the correlation between the 5-HTR1A gene polymorphism and pain intensity, the affective component of pain, pain related depression and anxiety in FMS.

Key words: Fibromyalgia; serotonin-1A receptor polymorphism (rs6295); pain intensity, pain related depression and anxiety.

Reumatismo, 2021; 73 (1): 24-31

\section{INTRODUCTION}

$\checkmark$ ibromyalgia syndrome (FMS) is a severely debilitating chronic pain syndrome. It is defined by widespread musculoskeletal pain, for more than three months, and accompanied by auxiliary symptoms, like joint stiffness, chronic fatigue, unrefreshing sleep, depression, anxiety and cognitive malfunction (1). Genetic predisposition plays an important role in the progression of FMS (2). Previous studies on genetic vulnerability in FMS reported a dysregulation of central serotonergic metabolism, and reduced serotonin (5-HT) metabolites in the cerebrospinal fluid (3). Several studies have also shown potential association between FMS and polymorphisms in serotonin-related genes, further corroborating the fact that the serotonergic system is markedly involved in the modulation of homeostatic, affective and painrelated mechanisms (4). A previous study has suggested that serotonin is essential in the regulation of anxiety, fear, and also in the tendency to commit suicide and other violent actions (5). These behaviours are mediated by at least 14 different serotonin receptors (6). Additionally, the serotonin$1 \mathrm{~A}$ receptor (5-HTR1A) has been shown to 
help in detecting anxiety disorders as proven by the results of a clinical study showing that selective 5-HT1A receptor agonists are common tranquilizers (7).

5-HT1A receptors are vastly expressed in brain areas such as orbitofrontal cortex, amygdala, hippocampus, insula, cingulate cortex and midbrain raphe areas which are associated with affective and emotional processes (8). Altered 5-HT1A levels are also observed in major depressive disorder (9), bipolar disorder (10) and anxiety disorder (11).

Clinically, the partial 5-HT1A agonists and serotonin reuptake inhibitor are used to treat anxiety disorders (12) and depression (13).

Many genetic studies demonstrated that GG genotype or $\mathrm{G}$ allele carriers of the 5-HT1A gene promoter polymorphisms are associated with depression $(5,9)$ and may influence the response to antidepressant therapy $(14,15)$. Studies on major depression, anxiety, panic disorder, suicide and schizophrenia have also indicated the involvement of the $\mathrm{G}$ allele as a 'risk allele' $(5,14,16)$.

There is considerable concomitance between chronic pain and affective disorders (17) suggesting interlinked neurobiological pathways, such as potentially serotonergic deregulation (18).

These findings suggest that the relationship between FMS and polymorphisms in serotonin-related genes needs further clarification and might be favoured by psychiatric comorbidity. Though many studies have been conducted to find the involvement of the genes related to serotonergic pathways related to pain modulation, limited work has been focused on 5-HT1A receptor gene polymorphism in FMS. In our literature search, no study has observed the effect of 5-HTR1A (rs6295) interaction on pain, its various affective components, pain-related depression and anxiety. Therefore, in this study, HTRlA gene polymorphism was compared between patients with FMS and healthy volunteers and correlated with pain intensity, the affective component of pain, pain-related depression and anxiety.

\section{MATERIALS AND METHODS}

\section{Patient enrollment}

The study was conducted in the Pain Research and TMS Laboratory, Department of Physiology, All India Institute of Medical Sciences (AIIMS), New Delhi and was approved by the Institute Human Ethics committee (Ref No: IESC/T-251/15.06.2013). The current data is a part of one of the objectives of a doctoral thesis which included the investigation on the effect of repetitive transcranial magnetic stimulation on pain and its modulation (which was performed with subjective, objective pain assessment tools and biochemical markers) in FMS patients (24). All procedures performed during the study involving patients were in accordance with the ethical standards of the Human Ethics committee of the AIIMS, New Delhi.

Female patients with FMS (age 18-50 years) having regular menstrual cycle were recruited from the Rheumatology Clinic, at the Department of Rheumatology. The enrollment was based on the American College of Rheumatology (ACR) 1990 criteria for the classification of FMS (19). Age and gender matched healthy subjects were recruited among patient relatives and Institute staff. Only the subjects who were able to give written informed consent were enrolled in the study. The FMS patients were excluded from the study, if they were:

1) pregnant or lactating;

2) having irregular menstrual cycle;

3) having chronic systemic disease, inflammatory joint diseases, secondary FMS, seizures, history of trauma;

4) with a concomitant diagnosis of chronic fatigue syndrome and/or major psychiatric disorder, currently undergoing psychotherapy.

\section{Subjective assessment of pain and related symptoms:}

The pain intensity was evaluated by $\mathrm{Nu}$ merical Pain Rating Scale (NPRS) or NRS which is a 11-point numerical scale ranging from ' 0 ' meaning 'no pain' to ' 10 ' meaning 'pain as bad as you can imagine' or 'worst pain imaginable' (20). The multidimensional components of pain were 
assessed by McGill pain questionnaire (MPQ), which is designed to measure the sensory, affective and evaluative aspects of pain in adults suffering from chronic pain. The scale consists of 78 descriptive items categorized into 20 subclasses evaluating sensory (question 1 to 10), affective (question 11 to 15), evaluative (question 16) and miscellaneous components of pain (question 17 to 20) (21). Pain-related anxiety was evaluated by Hamilton Anxiety Rating Scale (HARS). It contains 14 items, each defined by a series of symptoms, and measures both psychic anxiety (psychological distress and mental agitation) and somatic anxiety (physical complaints related to anxiety). Each item is scored on a scale of 0 (not present) to 4 (severe), with a total score range of $0-56$, where $<17$ indicates mild anxiety, 18-24 mild to moderate anxiety and 25-30 moderate to severe anxiety (22). Pain-related depression was studied by utilizing Hamilton Depression Rating Scale (HDRS). Eight items are scored on a 5-point scale, ranging from 0 , 'not present' to 4, 'severe'. Nine items are scored 0-2. First 17 items are added to obtain the total score (23).

\section{Genotyping}

Blood samples were collected in EDTA tubes and stored at $-80^{\circ} \mathrm{C}$ until further use. DNA was extracted by using a DNA isolation kit (Qiagen) for the study of single nucleotide polymorphism. The DNA samples were stored at $-80^{\circ} \mathrm{C}$ for further analysis. For genotyping of the rs6295 $(-109 \mathrm{C} / \mathrm{G})$; A 544-bp fragment of the 5-HT1A gene was amplified using primers 5-HTR1A Forward:5' - CACAAACGTAGTGGGAAGTGGC-3' and 5-HTR1A Reverse: 5'-GGAATTCCAACTACTCCTTGCCT-3'. The reaction mixture contained 100 ng DNA, $2.5 \mathrm{pM}$ of each primer, $100 \mathrm{mM}$ dNTPs and $1 \mathrm{U}$ Taqpolymerase in a final reaction volume of $25-\mu \mathrm{l}$. PCR amplification was carried out in a S1000TM thermal cycler under the following conditions: i. Initial denaturation: $95^{\circ} \mathrm{C}$ for $3 \mathrm{~min}$, ii. 35 cycles of denaturation at $95^{\circ} \mathrm{C}$ for 30 -s, iii. Annealing at $65^{\circ} \mathrm{C}$ for $40-\mathrm{s}$ iv. Extension at $72^{\circ} \mathrm{C}$ for 60 -s v. Final extension step at $72^{\circ} \mathrm{C}$ for $5 \mathrm{~min}$. vi. PCR products were checked for amplification on $1.5 \%$ agarose gel.

Restriction fragment length polymorphism (RFLP) analysis:

Amplified PCR products were digested with 2.5 U BtsCI (Fermentas, USA) and incubated at $37^{\circ} \mathrm{C}$ for $35 \mathrm{~min}$ and separated on $2.5 \%$ agarose gel. The 5-HTR1A-CC genotype was represented by fragments of $544 \mathrm{bp}$, the 5-HTR1A-CG genotype by fragments of 544bp, 488bp and 56bp and 5-HTR1A-GG genotype by fragments of 488bp and 56bp.

\section{Statistical analysis}

All the analyses were performed using IBM SPSS Statistics version 22.0 (IBM Statistics for Windows, Chicago, IL, USA) and graphs were created using Graphpad Prism version 5.01 for Windows, (GraphPad Software, San Diego, California, USA). All data was checked for normality using D'Agostino and Pearson's omnibus normality test. The Baseline scores of the parameters between healthy subjects and FMS groups were compared using unpaired t test/ Mann-Whitney U test. ChiSquare test was applied to assess statistical difference in frequency of genotypes of 5-HTRIA gene between healthy subjects and FMS patients. One Way ANOVA was applied to assess the statistical significance among the three genotypes with Tukey's Multiple Comparison Test. The $\mathrm{p}$ value of 0.05 or less was considered significant.

\section{RESULTS}

The subjective pain measures and blood samples were collected from 62 FMS patients and 42 healthy subjects [ $(\mathrm{n}=37)$ nonrelative controls; $(n=5)$ relatives of FMS patients]. 5-HTIA gene was represented by three different genotypes, homozygous $\mathrm{C} / \mathrm{C}$, heterozygous $\mathrm{C} / \mathrm{G}$ and homozygous G/G. In FMS, the analysis of the 5-HT1A gene showed a frequency of $58 \%, 31 \%$ and $11 \%$ for the $\mathrm{C} / \mathrm{C}, \mathrm{C} / \mathrm{G}$ and $\mathrm{G} / \mathrm{G}$ genotypes, respectively. This proportion was $69 \%$, $23 \%$ and $8 \%$ in the healthy subjects. There was no significant difference $(\mathrm{p}=0.27)$ between the two groups. However, the analysis demonstrated that the wild type ho- 
mozygous genotype is higher compared to the heterozygous genotype both in healthy subjects and FMS patients (Table I). There was a significant statistical difference in ratings of NPRS, HDRS and HARS be- tween healthy subjects and FMS patients (Table I). We also compared the NPRS, MPQ, HDRS and HARS ratings among the three genotypes, i.e. $\mathrm{C} / \mathrm{C}, \mathrm{C} / \mathrm{G}$ and $\mathrm{G} / \mathrm{G}$ of FMS patients. Ratings for pain and asso-

Table I - Comparison of general characteristics and rs6295 genotype (-1019C/G HTR1A) of serotonin receptor gene (5-HTR1A) in fibromyalgia (FMS) patients and healthy controls.

\begin{tabular}{|c|c|c|c|c|}
\hline Parameters & Units/Sub parameters & Healthy controls $(n=42)$ & FMS patients $(n=62)$ & ${ }^{*} p$ \\
\hline Age & Years & $37.69 \pm 7.757$ & $40.68 \pm 8.00$ & 0.06 \\
\hline Height & $\mathrm{cm}$ & $157.0 \pm 6.46$ & $155.9 \pm 5.584$ & 0.35 \\
\hline Weight & $\mathrm{Kg}$ & $64.71 \pm 10.80$ & $62.52 \pm 7.660$ & 0.23 \\
\hline Systolic BP & $\mathrm{mm} / \mathrm{Hg}$ & $115.0 \pm 6.65$ & $116.2 \pm 8.75$ & 0.46 \\
\hline Diastolic BP & $\mathrm{mm} / \mathrm{Hg}$ & $77.69 \pm 7.01$ & $76.98 \pm 6.94$ & 0.53 \\
\hline Pulse & n/Min & $65.0 \pm 7.86$ & $67.27 \pm 8.39$ & 0.16 \\
\hline Duration of pain & Year & - & $8.435 \pm 5.585$ & - \\
\hline Tender points & Number & $0.93 \pm 1.31$ & $14.0 \pm 2.76$ & 0.0001 \\
\hline Ethnicity & - & Indo-Aryan & Indo-Aryan & - \\
\hline \multirow{3}{*}{ Marital status } & Unmarried & $5 \%$ & $67 \%$ & - \\
\hline & Married & $92 \%$ & $31 \%$ & - \\
\hline & Divorcee & $3 \%$ & $2 \%$ & - \\
\hline \multirow{6}{*}{$\begin{array}{l}\text { Educational } \\
\text { status }\end{array}$} & Illiterate & $2 \%$ & $15 \%$ & - \\
\hline & Primary school & $5 \%$ & $24 \%$ & - \\
\hline & High school & $9 \%$ & $18 \%$ & - \\
\hline & Senior secondary & $9 \%$ & $9 \%$ & - \\
\hline & Graduation & $35 \%$ & $29 \%$ & - \\
\hline & Post-graduation & $40 \%$ & $5 \%$ & - \\
\hline \multirow{4}{*}{$\begin{array}{l}\text { Employment } \\
\text { status }\end{array}$} & Home-maker & $15 \%$ & $49 \%$ & - \\
\hline & Student & $41 \%$ & $5 \%$ & - \\
\hline & Employed & $39 \%$ & $35 \%$ & - \\
\hline & Self employed & $5 \%$ & $11 \%$ & - \\
\hline \multirow{3}{*}{ NPRS ratings } & - & $0.42 \pm 0.71$ & $7.38 \pm 1.10$ & 0.0001 \\
\hline & Sensory & - & $23.19 \pm 4.91$ & - \\
\hline & Affective & - & $7.000 \pm 2.75$ & - \\
\hline \multirow{4}{*}{$M P Q$ ratings } & Evaluative & - & $3.210 \pm 0.8896$ & - \\
\hline & Miscellaneous & - & $6.839 \pm 3.189$ & - \\
\hline & Total pain ratings & - & $40.24 \pm 6.201$ & - \\
\hline & Present pain intensity & - & $2.968 \pm 0.8291$ & - \\
\hline HDRS ratings & - & $8.60 \pm 3.12$ & $20.58 \pm 5.32$ & 0.0001 \\
\hline HARS ratings & - & $12.55 \pm 4.01$ & $22.31 \pm 6.24$ & 0.0001 \\
\hline \multirow{3}{*}{$\begin{array}{l}\text { Genotype } \\
\text { percentage }\end{array}$} & $\mathrm{CC}$ & $69 \%$ & $58 \%$ & \multirow{3}{*}{0.27} \\
\hline & CG & $23 \%$ & $31 \%$ & \\
\hline & GG & $8 \%$ & $11 \%$ & \\
\hline
\end{tabular}

Data is presented as Mean \pm SD or percent (\%). $p<0.05$ was considered to be statistically significant. 


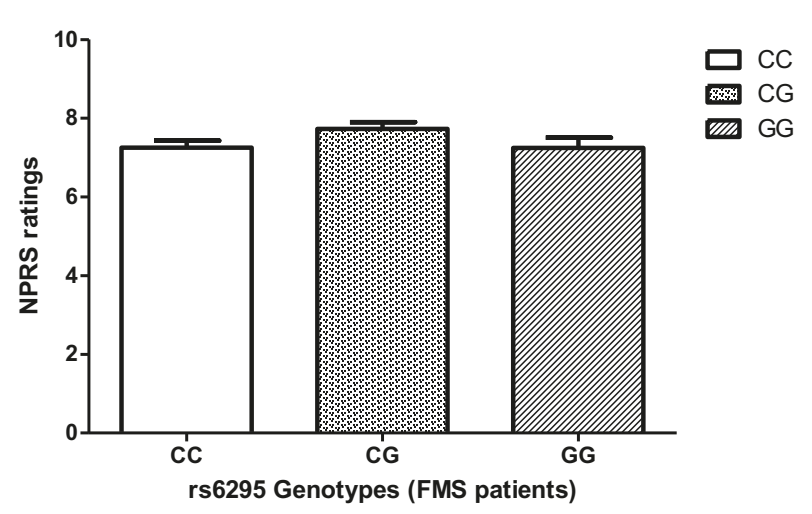

Figure 1 - NPRS ratings of rs6295 genotypes (CC, CG, GG) of the 5-HTR1A gene among FMS patients.

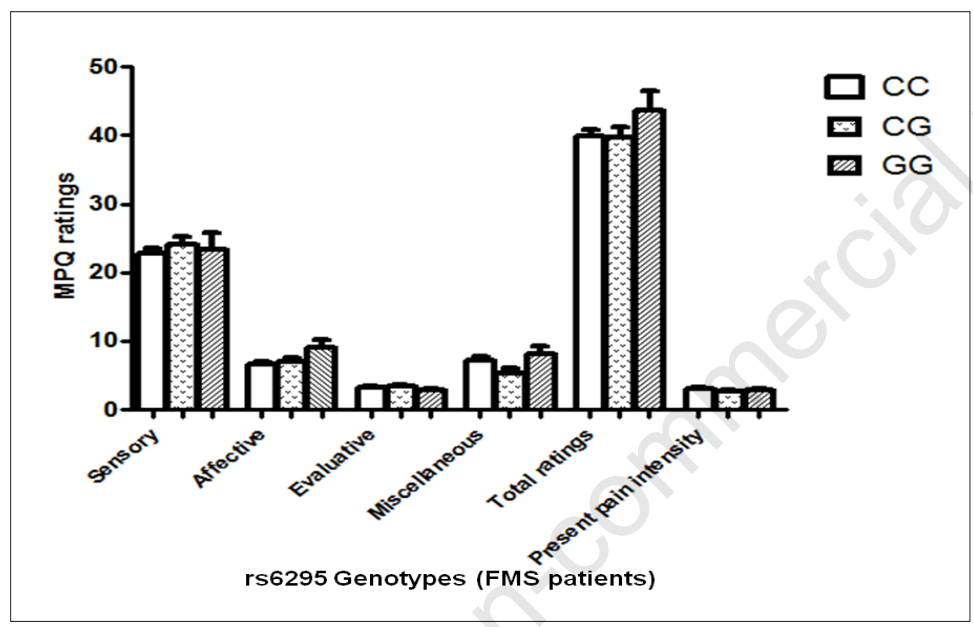

Figure 2 - McGill pain questionnaire (MPQ) ratings of rs6295 genotypes (CC, CG, GG) of the 5-HTR1A gene among FMS patients. ciated symptoms were comparable among the $\mathrm{C} / \mathrm{C}, \mathrm{C} / \mathrm{G}$ and $\mathrm{G} / \mathrm{G}$ of $\mathrm{FMS}$ patients (Figures 1-4).

\section{DISCUSSION}

In the current study, rs6295 genotypes of 5-HTRIA gene were compared between healthy subjects $(\mathrm{n}=42)$ and FMS group $(\mathrm{n}=62)$ and no significant difference was observed between them. Numerical Pain Rating Scale, McGill Pain questionnaire, Hamilton Depression and anxiety scale ratings were also comparable among the three genotypes, i.e. $\mathrm{C} / \mathrm{C}, \mathrm{C} / \mathrm{G}$ and $\mathrm{G} / \mathrm{G}$ of FMS patients. Our findings are in line with previous research that could not observe an association between 5-HTRIA gene polymorphism and major depression (16) and anxiety in alcohol-dependent subjects (34). In contrast with our findings, a previous study reported a strong relationship between the $\mathrm{G}$ allele with anxiety-related features of neuroticism and harm avoidance in healthy participants (16). Previous research has shown that G-allele of HTRIA gene polymorphism was found to be over expressed in suicide (5), and was related to reduced sensitivity to drugs used for depression (14). Another study on the gene polymorphism of the substance $\mathrm{P}$ receptor (TACR1), dopamine transporter (DAT) and alpha1-antitrypsin (AAT) did not report any variations among the FMS patients suggesting that these genes may not be directly

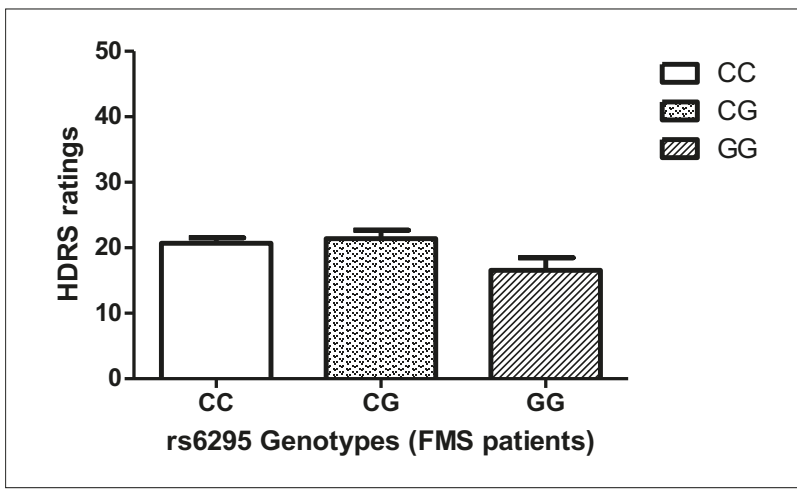

Figure 3 - Hamilton depression rating scale (HDRS) ratings of rs6295 genotypes (CC, CG, GG) of the 5-HTR1A gene among FMS patients.

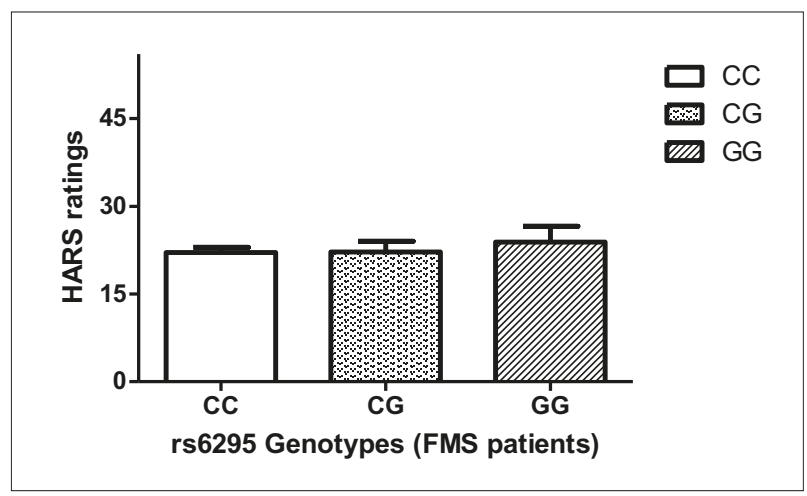

Figure 4 - Hamilton anxiety rating scale (HARS) ratings of rs6295 genotypes (CC, CG, GG) of the 5-HTR1A gene among FMS patients. 
linked to the etiopathology of FMS (25). A study on serotonin receptors (1A and $2 \mathrm{~A}$ ) has previously shown that gene promoter variations have gender-specific modulatory sequels on the depression of pain patients (26). These studies inferred that pain sensitivity, mood regulation and stress response can have common inherited-genetic factors; however, we could not find such a correlation. In a recent animal study with an intermittent psychological stress (IPS) model, the authors suggested that the lysophosphatidic acid receptor 1 (LPAI) gene plays a substantial role in IPS-induced fibromyalgia-like pain (27). These results suggest that the effect of 5-HTR1A on pain, depression and anxiety could be influenced by many other factors. The impact of 5-HTR1A on perception and/or its inhibition of pain is probably indirectly modulated by $5-H T 1 R A$ gene polymorphism and also associated with other serotonin receptors genes. This may explain our negative results. However, the probable effect of 5-HTIRA gene polymorphism on pain and pain-related depression and anxiety needs to be explored. Furthermore, serotonin affects pain modulation by genes controlling its metabolic enzymes/ receptors, like serotonin2A or 5-HT3R, but not by genes managing its $5 \mathrm{HT} 1 \mathrm{~A}$ receptor (28). This has been indicated by the effectiveness of 5-HT3 antagonists in the treatment of FMS (29). Additionally, an earlier study (30) observed a relationship between the 5-HT2A receptor gene polymorphism and FMS though other authors could not identify such an association (31). A recent study evaluated the effects of mu-opioid receptor $(O P R M 1)$ gene, the serotonin transporter $(5-H T T)$ gene $(5-H T T L P R)$ and serotonin-1a receptor (5-HTla) gene on exercise-induced hypoalgesia (EIH); and observed no specific impact on EIH in FMS patients, but rather an interaction between these genes and mu-opioid receptor signalling (32). Therefore, it can be inferred that serotonin does not produce elementary influences on pain, but causes various changes on pain depending on the downstream receptors (28).

Moreover, genetic factors are known to affect vulnerability to FMS, but no particular genes have been convincingly associated with the pathogenesis of FMS (33). Since our study was conducted on a limited sample size, it is not possible to comment upon the correlation between genetic predisposition and FMS. Other probable reasons for these findings could be the inclusion of FMS patient relatives as controls and the lack of functional analysis of the gene studied. In addition, only a limited number of genetic studies with 5-HTR1A and FMS can be found in the literature. The correlation of serotonin transporter gene polymorphisms and other 5-HT receptor genes with pain, pain-related depression and anxiety should be explored in the future. We are the first to evaluate the correlation between 5-HTR1A gene polymorphism and pain intensity, the affective component of pain, pain-related depression and anxiety.

\section{CONCLUSIONS}

We could not observe a correlation between the 5-HTRIA gene polymorphism and the main features of FMS (chronic pain, painrelated depression/anxiety) as studied with NPRS, MPQ, HDRS and HARS. Moreover, the frequencies of 5-HTR1A genotypes between patients with FMS and healthy subjects were also comparable. We could not find a significant relationship between the 5-HTR1A polymorphism and FMS pain and associated symptoms. Our findings do not prove the hypothesis that pain and related symptoms of fibromyalgia syndrome are modulated by 5-HTR1A gene polymorphism. Therefore, more such studies should be undertaken in the future to draw firm conclusions.

\section{Acknowledgments}

Authors are thankful to all the contributors i.e. FMS patients and healthy subjects for their participation and technical staff of Pain research and TMS laboratory, Department of Physiology; Dr. Manoj Kumar, Post-Doctoral Fellow, Department of Anatomy, AIIMS, New Delhi.

\section{Funding}

Research work was supported by Univer- 
sity Grant Commission (UGC), New Delhi. First Author was awarded by UGC-Junior/ Senior Research fellowship grant (certificate no 2121130622) for her doctoral research by UGC, New Delhi, India.

\section{Conflict of interests}

The authors declare no potential conflict of interests.

\section{Authors' contributions}

RB takes responsibility for the integrity of the work as a whole, from inception of idea to final manuscript. ST, UK, RD and RB made primary contributions in study design, data acquisition, analysis and interpretation of data and preparation of the final manuscript. BM made notable contributions in data acquisition, analysis, interpretation and preparation of the final manuscript along with its critical revision. All authors discussed the results and approved the final version to be submitted for publication.

\section{REFERENCES}

1. Son CN, Kim SH, Chang HW, Kim JM. A neurometabolite study of chronic daily headache in patients with systemic lupus erythematosus using magnetic resonance spectroscopy: comparison with fibromyalgia patients and healthy controls. Korean J Intern Med. 2016; 31: 1171-7.

2. Buskila, D, Sarzi-Puttini, P, Ablin, JN. The genetics of fibromyalgia syndrome. Pharmacogenomics. 2007; 8: 67-74.

3. Russell IJ, Vaeroy H, Javors M, Nyberg F. Cerebrospinal fluid biogenic amine metabolites in fibromyalgia/fibrositis syndrome and rheumatoid arthritis. Arthritis Rheum. 1992; 35: 550-6.

4. Lucki I. The spectrum of behaviors influenced by serotonin. Biol Psychiat. 1998; 44: 151-62.

5. Lemonde S, Turecki G, Bakish D, et al. Impaired repression at a 5-hydroxytryptamine 1A receptor gene polymorphism associated with major depression and suicide. J Neurosci. 2003; 23:8788-99.

6. Barnes NM, Sharp T. A review of central 5-HT receptors and their function. Neuropharmacology. 1999; 38: 1083-152.

7. Goldberg HL, Finnerty RJ. The comparative efficacy of buspirone and diazepam in the treatment of anxiety. Am J Psychiatry. 1979; 136: 1184-7.

8. Kranz GS, Kasper S, Lanzenberger R. Reward and the serotonergic system. Neuroscience. 2010; 166: 1023-35.

9. Parsey RV, Oquendo MA, Ogden RT, et al. Altered serotonin 1A binding in major depression: a (carbonyl-C-11)WAY100635 positron emission tomography study. Biol Psychiatry. 2006; 59: 106-13.

10. Sullivan GM, Ogden RT, Oquendo MA, et al. Positron emission tomography quantification of serotonin-1A receptor binding in medication-free bipolar depression. Biol Psychiatry. 2009; 66: 223-30.

11. Lanzenberger RR, Mitterhauser M, Spindelegger $\mathrm{C}$, et al. Reduced serotonin-1A receptor binding in social anxiety disorder. Biol Psychiatry. 2007; 61: 1081-9.

12. Cohn JB, Rickels K. A pooled, double-blind comparison of the effects of buspirone, diazepam and placebo in women with chronic anxiety. Curr Med Res Opin. 1989; 11: 30420.

13. Wang SM, Han C, Lee SJ, et al. A review of current evidence for vilazodone in major depressive disorder. Int J Psychiatry Clin Pract. 2013; 17: 160-9.

14. Lemonde S, Du L, Bakish D, et al. Association of the C(-1019)G 5-HT1A functional promoter polymorphism with antidepressant response. Int J Neuropsychopharmacol. 2004; 7: 501-6.

15. Malaguti A, Rossini D, Lucca A, et al. Role of COMT, 5-HT(1A), and SERT genetic polymorphisms on antidepressant response to transcranial magnetic stimulation. Depress Anxiety. 2011; 28: 568-73.

16. Huang YY, Battistuzzi C, Oquendo MA, et al. Human 5-HT1A receptor C(-1019)G polymorphism and psychopathology. Int $\mathrm{J}$ Neuropsychopharmacol. 2004; 7: 441-51.

17. Clauw DJ. Fibromyalgia: an overview. Am J Med. 2009; 122: S3-S13.

18. Ruoff GE. Depression in the patient with chronic pain. J Fam Pract. 1996; 43: S25-34.

19. Wolfe F, Smythe HA, Yunus MB, et al. The American College of Rheumatology 1990 criteria for the classification of fibromyalgia: Report of the multicenter criteria committee. Arthritis Rheum. 1990; 33: 160-72.

20. Jensen MP, McFarland CA. Increasing the reliability and validity of pain intensity measurement in chronic pain patients. Pain. 1993; 55: 195-203.

21. Melzack R. The McGill pain questionnaire: major properties and scoring methods. Pain. 1975; 1: 277-99.

22. Hamilton M. The assessment of anxiety states by rating. Br J Med Psychol. 1959; 32: 50-5.

23. Hamilton, MJ. A rating scale for depression. Neurology Neurosurgery and Psychiatr. 1960; 23: 56-62.

24. Tanwar S, Mattoo B, Kumar U, Bhatia R. 
Repetitive transcranial magnetic stimulation of the prefrontal cortex for fibromyalgia syndrome: a randomised controlled trial with 6-months follow up. Adv Rheumatol. 2020; 60: 34.

25. Ablin JN, Bar-Shira A, Yaron M, Orr-Urtreger A. Candidate-gene approach in fibromyalgia syndrome: association analysis of the genes encoding substance $\mathrm{P}$ receptor, dopamine transporter and alpha1-antitrypsin. Clin Exp Rheumatol. 2009; 27: S33-8.

26. Lebe M, Hasenbring MI, Schmieder K, et al. Association of serotonin-1A and $-2 \mathrm{~A}$ receptor promoter polymorphisms with depressive symptoms, functional recovery, and pain in patients 6 months after lumbar disc surgery. Pain. 2013; 154: 377-84.

27. Ueda H, Neyama H. LPA1 receptor involvement in fibromyalgia-like pain induced by intermittent psychological stress, empathy. Neurobiol Pain. 2017; 1: 16-25.

28. Potvin S, Larouche A, Normand E, et al. No relationship between the ins del polymorphism of the serotonin transporter promoter and pain perception in fibromyalgia patients and healthy controls. Eur J Pain 2010; 14: 742-6.

29. Riering K, Rewerts C, Zieglgänsberger W. An- algesic effects of 5-HT3 receptor antagonists. Scand J Rheumatol. 2004; 33: 19-23.

30. Bondy, B, Spaeth, M, Offenbaecher, M, et al. The T102C polymorphism of the 5-HT2Areceptor gene in fibromyalgia. Neurobiol Dis.1999; 6: 433-9.

31. Tander B, Gunes S, Boke O, et al. Polymorphisms of the serotonin-2A receptor and catechol-O-methyltransferase genes: a study on fibromyalgia susceptibility. Rheumatol Int. 2008; 28: 685-91.

32. Tour J, Löfgren M, Mannerkorpi K, et al. Gene-to-gene interactions regulate endogenous pain modulation in fibromyalgia patients and healthy controls - antagonistic effects between opioid and serotonin-related genes. Pain. 2017; 158: 1194-203.

33. Xiao Y, Russell IJ, Liu YG. A brain-derived neurotrophic factor polymorphism Val66Met identifies fibromyalgia syndrome subgroup with higher body mass index and C-reactive protein. Rheumatol Int. 2012; 32: 2479-85.

34. Koller G, Bondy B, Preuss UW, et al. The C(-1019)G 5-HT1A promoter polymorphism and personality traits: No evidence for significant association in alcoholic patients. Behav Brain Funct. 2006; 2: 7. 